\title{
IMPROVEMENT OF THE ANTICORROSIVE PROPERTIES OF AN ALKYD COATING WITH ZINC PHOSPHATE PIGMENTS ASSESSED BY NSS AND ACET.
}

\author{
M. J. Gimeno a , M. Puig ${ }^{c}$, S. Chamorro ${ }^{\text {a }}$, J. Molina ${ }^{\text {c }}$, R.March ${ }^{\text {b }}$, E. Oro ${ }^{\text {b }}$, P. Pérez ${ }^{\text {, }}$, \\ J. J. Gracenea ${ }^{c}$, J. J. Suay ${ }^{\mathrm{c}}$
}

aMEDICIONES Y CORROSION S. L., Avda. Vicente Sos Baynat s/n, 12006 Castellón, Spain.

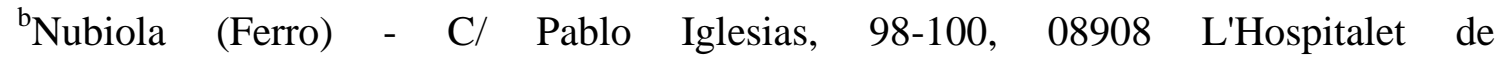
Llobregat (Barcelona), Spain.

${ }^{c}$ Polymers and Advance Materials Research Group (PIMA). University Jaume I. Avda. Vicente SosBaynat s/n, 12006 Castellón, Spain.

\section{*: mariajgimeno@medco.es}

\begin{abstract}
The effect of the addition of two anticorrosive phosphate pigments, standard zinc phosphate and modified zinc phosphate (zinc molybdenum phosphate modified with a surface treatment) on the corrosion protection of an alkyd coating on steel, has been investigated by means of a traditional accelerated test (salt fog spray test) and an electrochemical technique (accelerated cyclic electrochemical technique). Solvent-based alkyd coatings based on phenolic modified resins were formulated with different anticorrosive pigment concentrations $(3 \%, 4.5 \%$ and $6 \%$, expressed as anticorrosive pigment volume concentration in dry film volume, PVC) and finally characterised. An improvement in the anticorrosive properties is obtained with the addition of both pigments, the coatings formulated with modified zinc phosphate having better performance. Both techniques showed results that can be correlated.
\end{abstract}

\section{Introduction}

Alkyd-based coatings are among the most widely used anticorrosion systems because they are one-component curing paints, relatively inexpensive and can be formulated into both solvent-borne and waterborne coatings [1]. The protectiveness of alkyd coatings 
against corrosion has usually been enhanced by introducing inhibitors such as chromates [2], phosphates [3] and ion exchange pigments [4]. Nowadays, zinc phosphate derivatives are most frequently investigated, since conventional zinc phosphate was the first proposed non-toxic alternative to chromate-based corrosion inhibitors in paint formulations [5].

There are many explanations of the role that the zinc phosphate pigment plays in inhibiting the corrosion in the literature [6-9]. Many researchers agree that the mechanism of inhibition by this pigment is due to the formation of a passive oxide film on the metal surface, known as phosphatisation, as a result of the precipitation of insoluble compounds. This film reduces the rate of electrochemical processes since it can block active areas on the metal surface. Recently, Y. Hao et al. [10] demonstrated that the inhibition mechanism of zinc phosphate pigment in epoxy coating can be attributed to the synergistic effect of shielding and phosphatisation functions.

In recent decades, multiple physical and chemical modifications on zinc phosphate particles have been performed, resulting in novel generations of pigments, which have improved water solubility and corrosion inhibition performance [6,11-13]. Among them, zinc molybdenum phosphate is one of the most investigated due to a potential synergistic effect between phosphate and molybdate ions $[14,15]$. Several investigations have reported the use of zinc molybdenum phosphate as a non-toxic anticorrosive pigment in epoxy, polyester and acrylic systems [16-18]. Del Amo et al. [18] discussed the performance of different systems (acrylic, alkyd, epoxy and vinyl) where zinc molybdenum phosphate was incorporated using the same concentration for each system. However, zinc molybdenum phosphate in alkyd coatings has not yet been studied in detail.

Electrochemical techniques have become a fundamental tool for the evaluation of the anticorrosive effect of pigments integrated into coating formulations and applied on metal substrates. Although the accuracy of the salt fog spray test remains controversial $[1,19]$, it is also frequently used to complement electrochemical results, partly because its application constitutes the most common procedure performed by coatings manufacturers in coating lifetime prediction. Therefore, finding correlations between the results extracted from distinct characterisation methods deserves the attention of 
researchers aiming to validate the obtained values, although few studies focusing on this purpose have actually been reported [20,21].

The aim of this paper is to study the inhibitory effect of zinc phosphate and modified zinc phosphate pigments added to an alkyd formulation at different anticorrosive pigment volume concentration in the dry film volume. The formulations were tested on a steel substrate by means of the neutral salt spray test (NSS) and an accelerated cyclic electrochemical test (ACET). The results obtained by both techniques were correlated by means of a parameter based on the relative variations of the polarisation resistance $\left(\Delta \mathrm{Rp}^{*}\right)$.

\section{Experimental.}

\subsection{Substrate}

Standardised cold rolled steel panels S-46 from Q-Panel (CRS) were used in this study. The sample surface was degreased with acetone and coated with one layer of the paints to be tested.

\subsection{Pigments}

The pigments used were a standard zinc phosphate (NUBIOLA Nubirox N2) and a high performance zinc molybdenum phosphate with an organic surface treatment (NUBIOLA Nubirox 106).

\subsection{Coatings}

The coatings were applied with an application bar of $150 \mu \mathrm{m}$ wet film thickness on CRS panels and the thicknesses obtained were $67 \pm 3 \mu \mathrm{m}$. Prior to testing, the coatings were cured for one week at room temperature. Afterwards they were placed in a oven at $50^{\circ} \mathrm{C}$ for 24 hours.

Seven solvent based alkyd paints were formulated (Table 1), each of them containing an anticorrosive pigment at different dosages: $0 \%$ (Reference), 3\%, 4.5\% and 6\%, expressed as anticorrosive pigment volume concentration in dry film volume. The paint formulas were calculated keeping the same solids volume percentage (45\%) and the 
same PVC/CPVC ratio (0.70) (CPVC being the critical pigment volume concentration) in order to compare the pigment effect at the same free binder volume level.

Table 1: Formulations and physical parameters.

\begin{tabular}{|c|c|c|c|c|c|c|c|}
\hline & 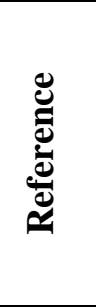 & 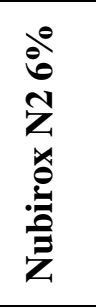 & 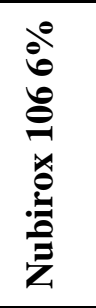 & 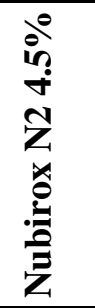 & 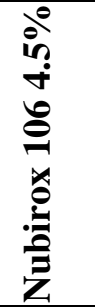 & 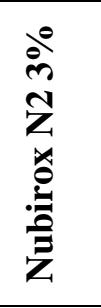 & 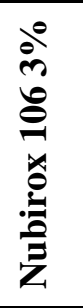 \\
\hline Bentone 34 , gel $10 \%$ in xylene & 4.38 & 4.31 & 4.38 & 4.32 & 4.38 & 4.34 & 4.38 \\
\hline Titanium Dioxide RD3 & 5.09 & 5.00 & 5.09 & 5.02 & 5.09 & 5.05 & 5.09 \\
\hline Anticorrosive pigment & 0.00 & 7.08 & 6.98 & 5.33 & 5.23 & 3.57 & 3.49 \\
\hline Calcium Carbonate MIBER A10 & 18.59 & 15.20 & 14.10 & 16.03 & 15.22 & 16.89 & 16.35 \\
\hline Talc Finntalc M05SL-AW & 12.62 & 10.32 & 9.57 & 10.89 & 10.33 & 11.47 & 11.10 \\
\hline Synolac 7503X60 & 20.36 & 19.63 & 21.32 & 19.81 & 21.08 & 20.00 & 20.84 \\
\hline Nusa 57 & 0.37 & 0.38 & 0.36 & 0.38 & 0.36 & 0.37 & 0.36 \\
\hline Xylene & 17.63 & 17.47 & 17.28 & 17.51 & 17.37 & 17.55 & 17.45 \\
\hline Synolac 7503X60 & 17.79 & 17.48 & 17.78 & 17.56 & 17.79 & 17.62 & 17.77 \\
\hline Octasoligen 27 & 0.59 & 0.58 & 0.61 & 0.58 & 0.60 & 0.58 & 0.60 \\
\hline Antiskinning & 0.18 & 0.19 & 0.18 & 1.19 & 0.18 & 0.19 & 0.18 \\
\hline Dowanol PM & 2.40 & 2.37 & 2.36 & 2.38 & 2.37 & 2.38 & 2.38 \\
\hline TOTAL & 100 & 100 & 100 & 100 & 100 & 100 & 100 \\
\hline PVC & 35.58 & 36.25 & 33.95 & 36.08 & 34.35 & 35.93 & 34.78 \\
\hline$\lambda=\mathrm{PVC} / \mathrm{CPVC}$ & 0.7 & 0.7 & 0.7 & 0.7 & 0.7 & 0.7 & 0.7 \\
\hline \%Solids (in volume) & 45.00 & 45.00 & 45.00 & 45.00 & 45.00 & 45.00 & 45.00 \\
\hline \%Solids (in weight) & 60.63 & 61.28 & 60.65 & 61.62 & 60.64 & 60.96 & 60.64 \\
\hline
\end{tabular}

The base mill was ground with glass balls of $3 \mathrm{~mm} \varnothing$ in an orbital shaker for 20 minutes to assure a fineness of grinding lower than $20 \mu \mathrm{m}$.

\subsection{Testing methods and equipment}

\subsubsection{Neutral Salt Spray Test (NSS).}

The neutral salt spray test (NSS) was performed according to ASTM B-117[22] in a salt fog chamber $400 \mathrm{SSC}$ (Dycometal) under the conditions of $(35 \pm 2)^{\circ} \mathrm{C}, 6.5-7.2$ units of $\mathrm{pH}$ and a salt fog with $5 \%$ (in weight) of sodium chloride water solution. A single vertical scratch of $6.5 \mathrm{~cm}$ long and of $0.1 \mathrm{~mm}$ wide was made on the coating surface using a carbide-tipped pencil-type tool prior to placing the samples into the chamber. The coated samples were left inside the chamber for 641 hours. After this time of 
exposure, the three replicates of each sample were dried for 24 hours at room temperature and "cross cut" [23] adhesion, adhesion at the scribe [24], rusting at the scribe [24] and rusting on the panel [25] were evaluated.

\subsubsection{Cross cut adhesion (ASTM B-3359).}

Dry coating adhesion to the substrate is measured by performing a cross cut of scribes on the coating until reaching the substrate and applying a standard adhesive tape to remove it.

\subsubsection{Adhesion at the scribe (ASTM D 1654-92-B).}

The loss of adhesion at the scribe can be related to the cathodic delamination. In this test a standard tape is applied on the scribe, after 24 hours of ambient exposure, to quantify the adhesion loss.

\subsubsection{Rusting at the scribe (ASTM D 1654-92-A)}

By measuring the millimetres of corrosion at the scribe, it is possible to see the anticorrosive pigment effectiveness in slowing down corrosion. The evaluation consists of removing the coating in one half panel and measuring the rusting in $\mathrm{mm}$ from one side of the scribe.

\subsubsection{Rusting on the panel (ASTM B-610-01)}

In this evaluation the coating is removed from one half of the panel and the percentage of rusted surface is estimated.

The anticorrosive protection value (global ranking) of a coating is an internal parameter of Nubiola (Ferro) and is not standardised. It is a combination of the rusting and adhesion results and it can be defined mathematically as:

GLOBAL RANKING =0.8 x Rusting Ranking + $0.2 \times$ Adhesion Ranking

Where:

Rusting Ranking $=$ (Classification $0-10$ Rusting on the panel ASTM D610 + Classification 0-10 Rusting at the scribe ASTM D1654)/2 
Adhesion Ranking $=($ Classification $0-10$ Adhesion at the scribe ASTM D1654 + Classification 0-10 Adhesion Cross cut ASTM D1654)/2

They found that the ratio $0.8 / 0.2$ gave them a better correlation with the simple visual observation of the sample.

\subsubsection{Accelerated Cyclic Electrochemical Technique (ACET)}

The accelerated cyclic electrochemical test (ACET) procedure measures the quality of the coating and its adhesion to the substrate by studying the resistance that the system offers to its degradation with cathodic polarisations [16]. The ACET was performed in accordance with UNE-EN ISO 17463 [26]. In this test, the coatings come into contact with the electrolyte and, after an initial characterisation by electrochemical impedance spectroscopy (EIS), they undergo, under controlled parameters that allow a comparison, six cycles of the following three steps (see Figure 1):

- Cathodic polarisation (1 Polarisation)

- Potential relaxation (2 relaxation time)

- $\quad$ Final EIS measurement (3 EISn)

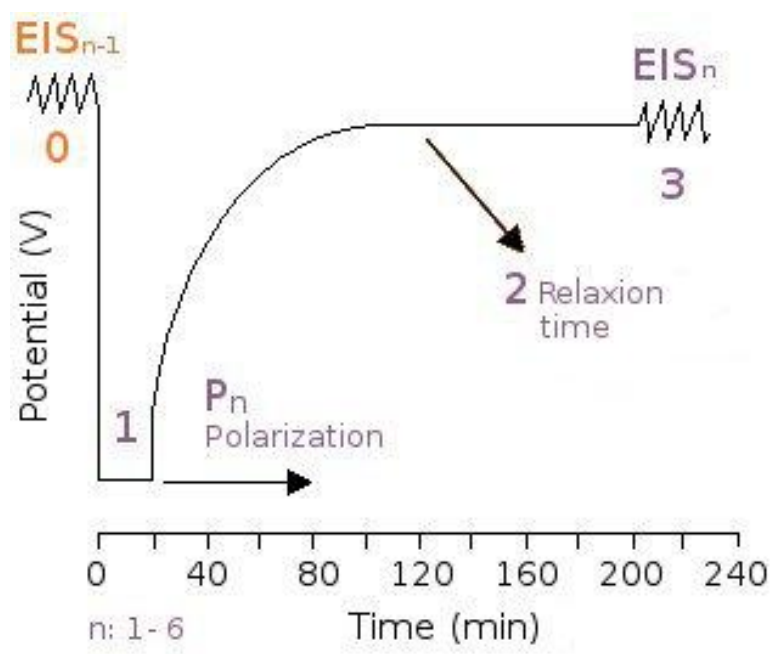

Fig. 1. ACET test schematic figure versus time.

ACET measurements were performed on a ZAHNER-IM6ex electrochemical workstation. The test was done in a three-electrode corrosion cell, using the bare substrate as a working electrode, a silver/ silver chloride $(\mathrm{E}=+0.197 \mathrm{~V}$ saturated vs NHE) reference electrode and a platinum counter electrode. The electrolyte used was a solution of $3.5 \% \mathrm{NaCl}$ (by weight). The coating exposure area for testing was $9.62 \mathrm{~cm}^{2}$. 
For this study, the EIS tests were carried out over a scanning frequency range from 100000 to $0.01 \mathrm{~Hz}$ and the amplitude of the signal was $12.5 \mathrm{mV}$ with respect to the open circuit potential. The cathodic polarisation was carried out for 20 minutes at a constant voltage of a $-2 \mathrm{~V} / \mathrm{Ag} / \mathrm{AgCl}$ and the stabilisation period (where the open circuit voltage evolution with time is also registered) lasted 180 minutes. The measurements were done on two coated replicas and inside a Faraday cage in order to minimise external interferences on the system. When the results were coincident, one of them was used to represent the Bode plot; in the case of some difference between replicas, a third replica was selected and of the two coincident replicas, one was used for analysis.

The impedance spectra were obtained and analysed using MedCo and Z-view software, respectively. Interpretation of impedance data was done by designing equivalent circuits (as in Fig. 2) which are built up from an appropriate combination of simple electrical elements, based on the use of circuits representing the dielectric properties of the layers and the electrochemical processes occurring at the metal/electrolyte interface [27].

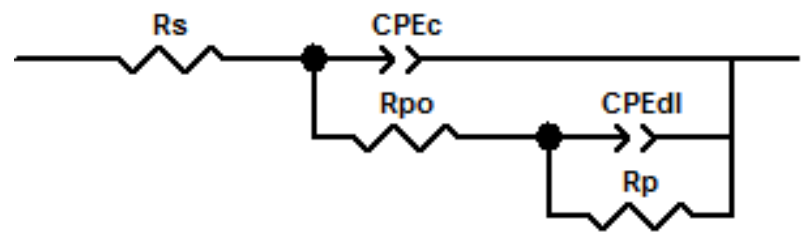

Fig. 2. Equivalent circuit used to model ACET impedance data where passive parameters $(R s=$ electrolyte resistance, $R p o=$ pore resistance, $C P E c=$ constant phase element of the coating capacitance,

$R p=$ polarisation resistance and $C P E d l=$ constant phase element of the double layer capacitance).

The first parameters are related to the coating (pore resistance, Rpo, can be associated to porosity and the deterioration of the coating and constant phase element of the coating capacitance, $C P E c$, to the water uptake of coatings) and correspond to processes which occur at high frequencies; the second parameters give information about the interface ( $R p$ can be associated with the polarisation resistance of the interface between the coating and the metal substrate; the constant phase element of the double layer capacitance, $C P E d l$, can be associated with the disbonding of the coating and onset of corrosion at the interface) and correspond to processes which take place at low frequencies [16].

As mentioned above, the fitting results of the parameters of the equivalent circuit were obtained using the software ZView. The chi-squared parameter $\left(\chi^{2}\right)$ of the fit was 
usually below 0.1 . When modelling the equivalent circuit with CPE, the software gave values of capacitance in units $\mathrm{s}^{\mathrm{n}} / \Omega$, together with a parameter known as " $\mathrm{n}$ ". When $\mathrm{n}$ is close to 1 (ideal capacitor), it can be considered that the values for capacitances given by the software match the effective capacitances (ideal).

\section{Results and discussion.}

\subsection{Neutral Salt Spray Test (NSS)}

Fig. 3 shows the image of the alkyd coatings without pigment (Reference) obtained after the exposure of the samples to neutral salt fog into a chamber for 641 hours. The scratched area of the Reference coating presents a considerable delamination, which indicates poor adhesion between the coating and the substrate after the exposure.

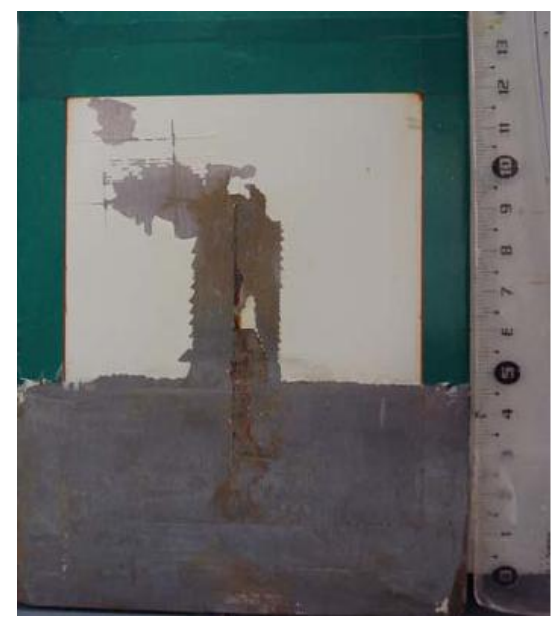

Fig. 3. Photograph of the Reference panel after 641 hours in the salt spray chamber.

Table 2 shows the quantitative rusting and adhesion results for the samples tested. Nubirox N2 and Nubirox 106 were added at different anticorrosive pigment volume concentration (PVC). When any of the pigments were added to the Reference formulation, especially in the case of Nubirox 106, a significant decrease in the rusting at the scribe parameter and in the two parameters referring to the adhesion (delamination at the scribe and on the panel, measured as a maximum value) was seen. According to the global ranking (eq.1), coatings including Nubirox N2 and Nubirox 106 pigments achieved better performance than the Reference coating. These results indicate an increase of the anticorrosive protection because of pigment addition, and a better anticorrosive performance with the content increase of anticorrosive pigment. 
Both evaluated pigments have a positive effect in the Reference formulation, leading to reduction in rusting at the scribe and delamination on the panel for all considered concentrations, especially for delamination in the case of Nubirox 106 pigment (delamination at the panel is reduced close to zero). In other studies of epoxy coatings [16] Nubirox 106 also offered very good results. The NSS test confirmed that the alkyd coating containing 6\% volume fraction of Nubirox 106 had the best protection ability.

Table 2: Results of formulated coatings after exposure for 641 hours to salt spray (distilled water with 5 $\mathrm{wt} \% \mathrm{NaCl})$.

\begin{tabular}{|c|c|c|c|c|c|c|c|}
\hline Pigment & $\begin{array}{l}\text { Rusting at the } \\
\text { scribe (mm) } \\
\text { (ASTM D } \\
\text { 1654-92-A) }\end{array}$ & $\begin{array}{c}\text { Rusting on } \\
\text { the panel (\%) } \\
\text { (ASTM B- } \\
610-01)\end{array}$ & $\begin{array}{c}\text { Rusting } \\
\text { Ranking* }\end{array}$ & $\begin{array}{l}\text { Delamination at } \\
\text { the scribe }(\%) \\
\text { (ASTM D 1654- } \\
\text { 92-B) }\end{array}$ & $\begin{array}{l}\text { Delamination on } \\
\text { the panel }(\%) \\
\text { (ASTM B-3359) }\end{array}$ & $\begin{array}{l}\text { Adhesion } \\
\text { Ranking* }\end{array}$ & $\begin{array}{c}\text { Anticorrosive } \\
\text { protection } \\
\text { Global } \\
\text { Ranking* }\end{array}$ \\
\hline REFERENCE & $3.5 \pm 0.0$ & $0.1 \pm 0.00$ & $7 \pm 0$ & $100 \pm 0$ & $73 \pm 46$ & $1 \pm 1$ & $5 \pm 0$ \\
\hline Nubirox N2 6\% & $2.5 \pm 0.0$ & $0.05 \pm 0.04$ & $7 \pm 0$ & $43 \pm 6$ & $35 \pm 48$ & $4 \pm 3$ & $7 \pm 1$ \\
\hline Nubirox $1063 \%$ & $2.3 \pm 0.6$ & $0.05 \pm 0.04$ & $8 \pm 1$ & $27 \pm 15$ & $0 \pm 0$ & $7 \pm 1$ & $8 \pm 0$ \\
\hline Nubirox $1064.5 \%$ & $2.2 \pm 0.3$ & $0.03 \pm 0.00$ & $8 \pm 0$ & $23 \pm 6$ & $1 \pm 1$ & $7 \pm 0$ & $8 \pm 0$ \\
\hline
\end{tabular}

*non standardised evaluation.

\subsection{Accelerated Cyclic Electrochemical Technique (ACET)}

Fig. 4 a-c show the Bode plots corresponding to the reference coating, Nubirox N2 and Nubirox 106 coatings at $6 \%$ in the alkyd formulations after six cathodic polarisations, respectively.

Coatings containing inhibitory pigments exhibited a higher impedance modulus after six polarisation cycles were applied. The variation of the impedance value at low frequency (i.e. $0,1 \mathrm{~Hz}$ ) was reduced during the cycles, when compared to the reference coating. Regarding the frequency sweep, the capacitive behaviour of Nubirox 106 containing coating is more obvious, since the first region of the phase angle line remains constant at around $-90^{\circ}$ until lower frequency values. 


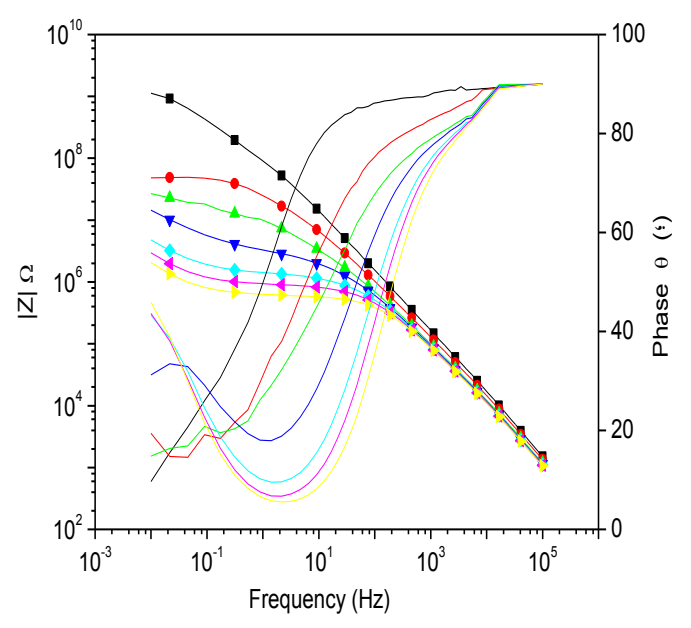

(a)

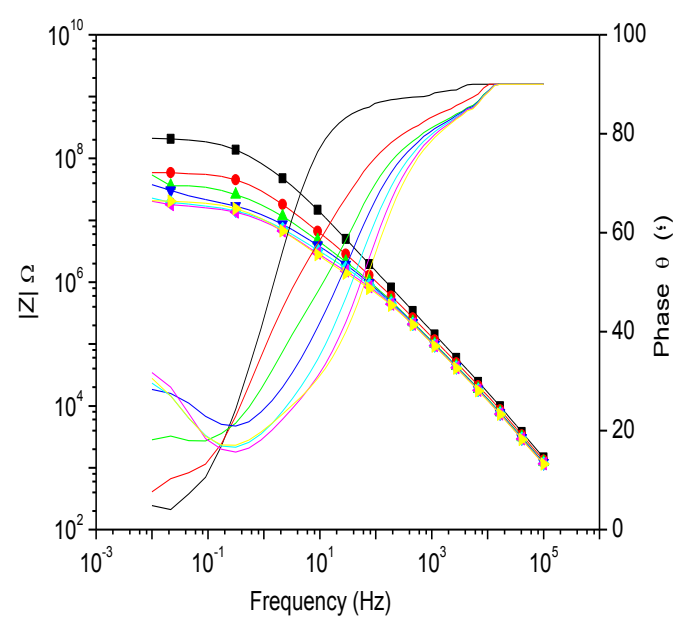

(b)

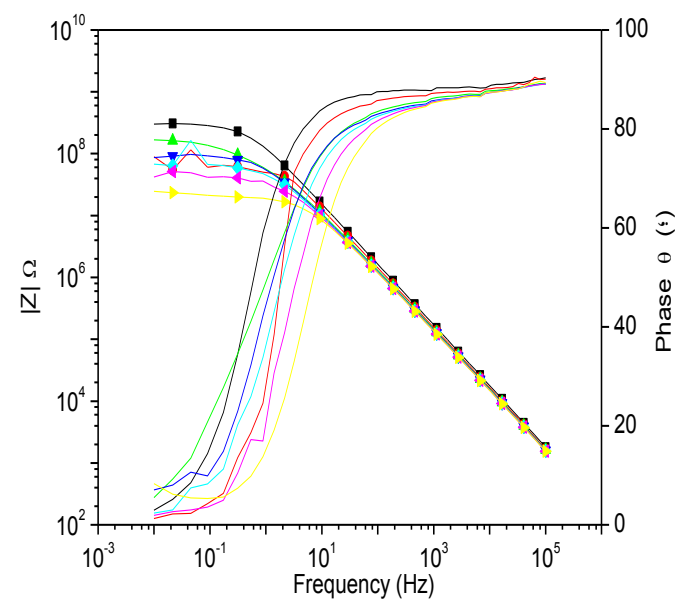

(c)

Fig. 4. Evolution of Bode spectrum with the cycles of ACET (cycle: $0(\bullet), 1(\bullet), 2(\triangle), 3(\nabla), 4(\diamond)$, $5(\varangle)$ and $6(>)$ for a) Reference; b) Nubirox N2 6\% and c) Nubirox $1066 \%$ coating. 
The electrical equivalent circuit shown in Fig. 2 and the Z-View software were used to fit the impedance data obtained in the ACET test and to model the behaviour of the different coatings with anticorrosive pigments applied onto the steel and in contact with electrolyte. Fig. 5 shows the excellent concordance between the experimental results (impedance modulus and phase) and the modelled values over the whole frequency range studied.

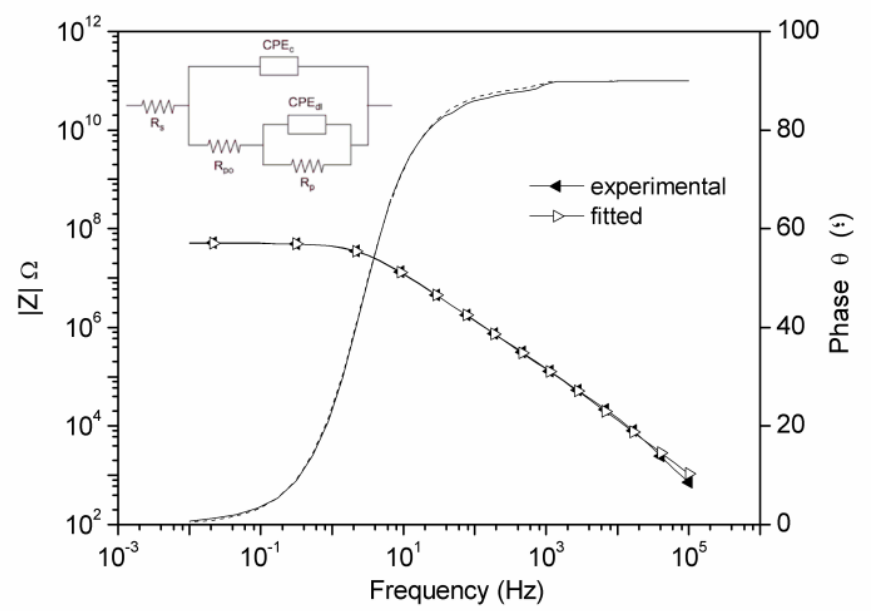

Fig. 5. Experimental and fitted data of coating with Nubirox $1066 \%$.

Fig. 6 and Fig. 7 show the evolution of the equivalent circuit parameters with the polarisation cycles applied to Nubirox N2 and Nubirox 106 coatings, respectively. The results of coating capacitance $C P E c$ are not shown because they barely present significant variations and do not show any clear tendency in the values with the cycles (the obtained values are between $6 * 10^{-10}$ and $1.4 * 10^{-9}$ ).

It can be observed that the pore resistance, Rpo, is higher at cycle 0 for coatings with Nubirox N2 (Fig 6a) in comparison with the reference coating, although its value decreases with the applied polarisation stress probably due to coating degradation. The pigment percentages do not seem to exercise any influence on the $C P E d l$ values, as all coatings show a similar trend (Fig. 6c). The increase of CPEdl with the cycles applied can be related to intensification of the delamination processes. In contrast, the pigment content has a significant effect on the polarisation resistance parameter, its values increase with the pigment content, possibly due to the formation of a passive layer on the substrate surface. It is remarkable that the evolution of $R p$ remained almost constant during the polarisation cycles for the $6 \%$ Nubirox N2 coating indicating high stability of the passive layer formed. 
Nubirox 106 does not lead to any significant improvement in the Rpo values (Fig. 7a). In fact, the main effect of the pigment content is on the interphase between the coating and the substrate. The anticorrosion properties of the coating improve when the pigment dose is increased, 6\% PVC giving the highest polarisation resistance values ( $R p$, Fig $7 \mathrm{~b}$ ) and the lowest double layer values (CPEdl, Fig. 7c) that are indicative of high interface stability and reduced coating delamination, respectively. Variation in the values of $R p$ and $C P E d l$ with the cycles is reduced when the pigment content is increased.

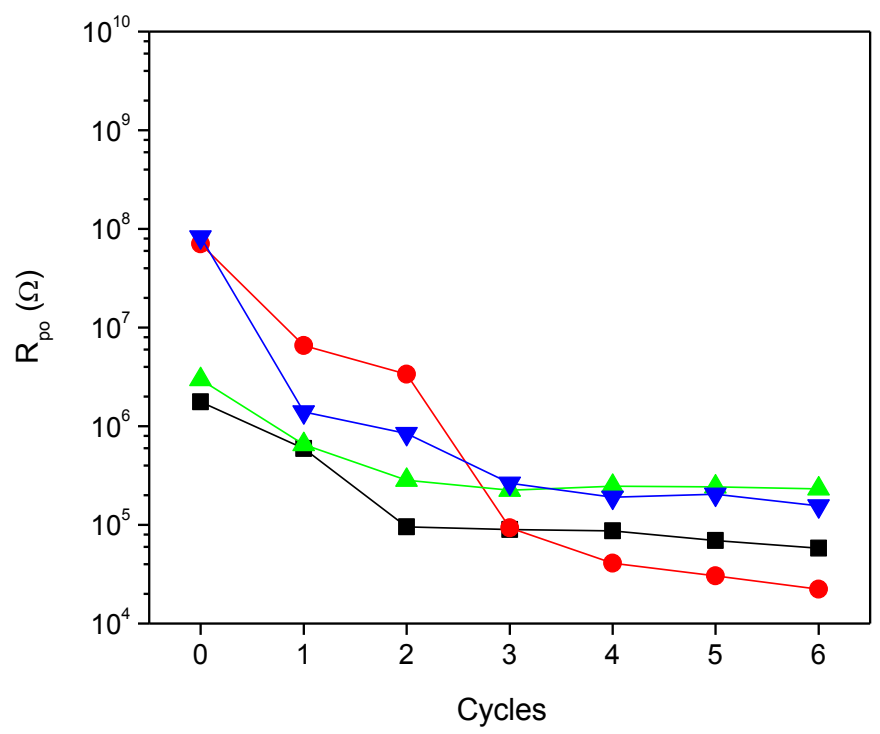

(a)

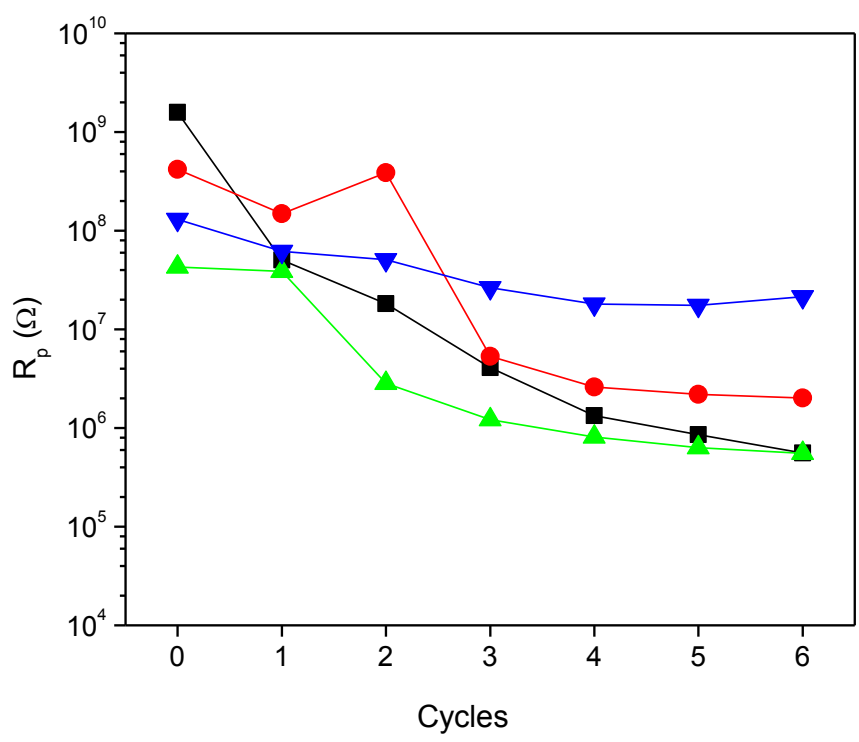

(b) 


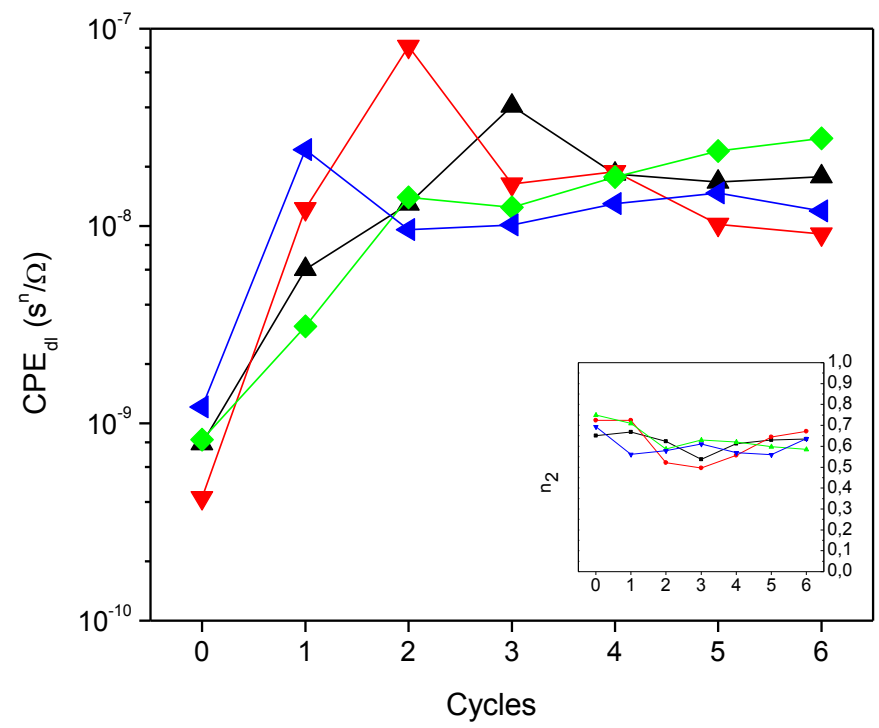

(c)

Fig. 6 (a) Evolution of pore resistance, Rpo; (b) polarisation resistance, $R p$; (c) double layer capacitance, $C P E d l$ vs. the number of cycles for alkyd coatings with different pigment content: Reference ( $\boldsymbol{\square})$,

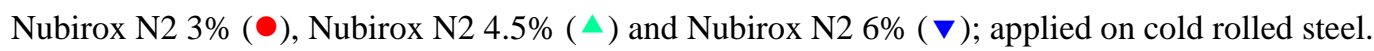

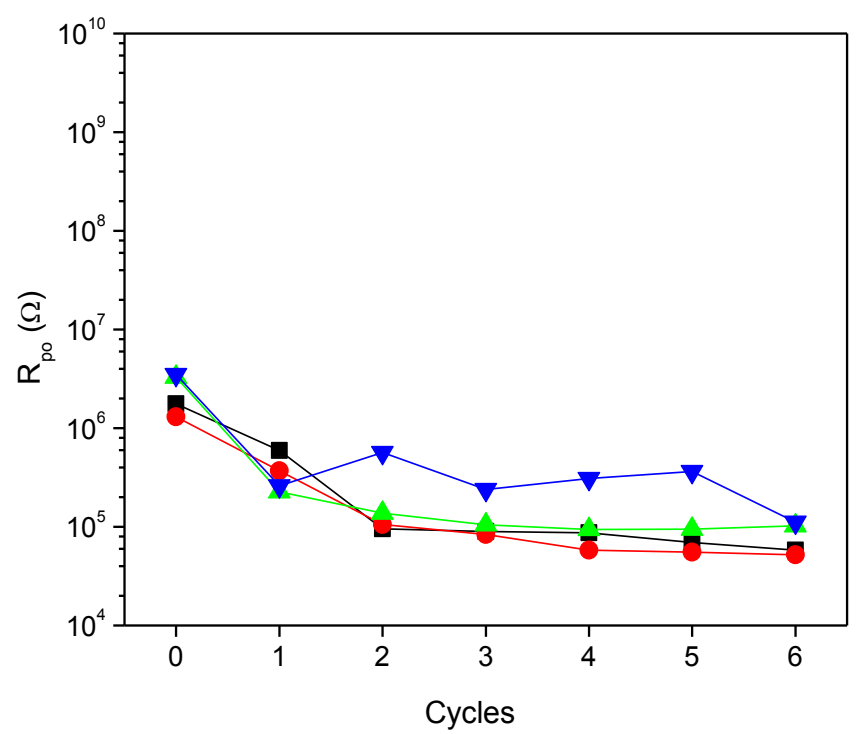

(a) 


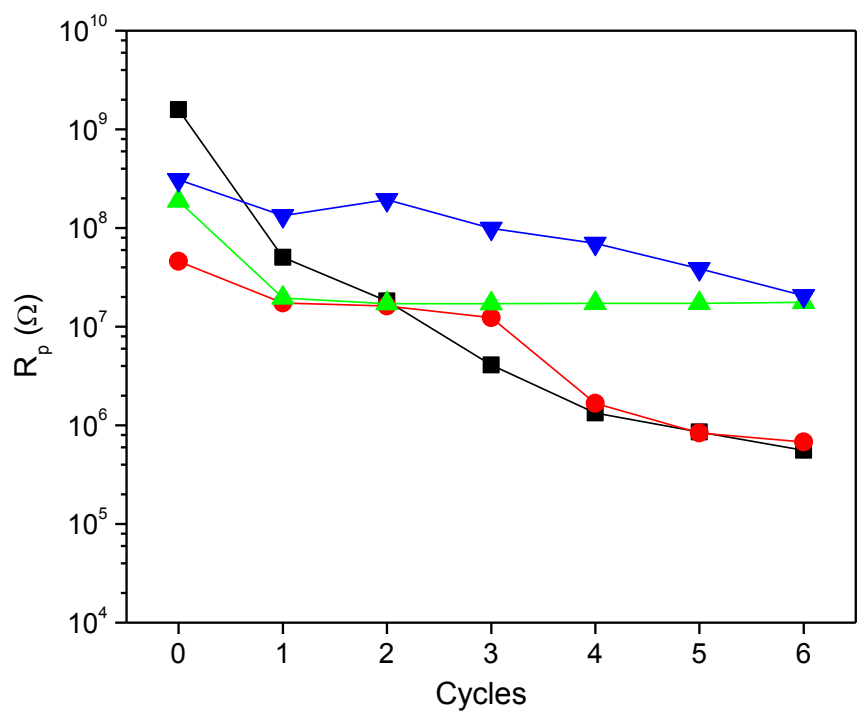

(b)

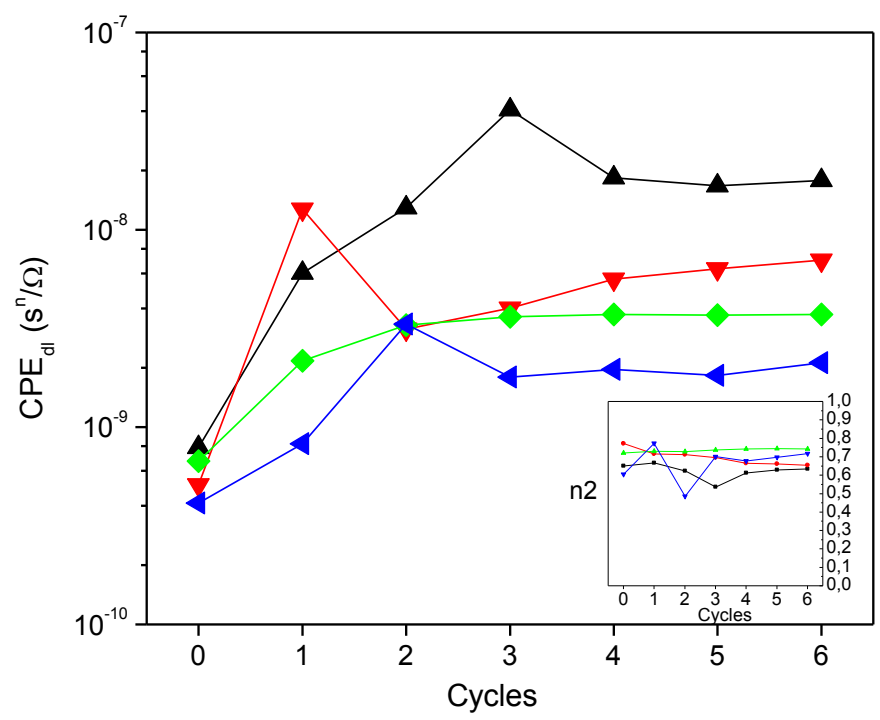

(c)

Fig. 7. (a) Evolution of pore resistance, $R p o$; (b) polarisation resistance, $R p$; (c) double layer capacitance, $C P E d l$ vs. the number of cycles for alkyd coatings with different pigment content: Reference ( $\square$ ), Nubirox 106 3\% (•), Nubirox $1064.5 \%(\triangle)$ and Nubirox 106 6\% ( $\nabla)$; applied on cold rolled steel.

In order to extend the quantitative study of the anticorrosive behaviour at different anticorrosive pigment concentrations, a new parameter $\Delta R p^{*}$ was introduced. $\Delta R p^{*}$ is a 
relative measurement of the polarisation resistance variation in the coatings during the accelerated cyclic electrochemical test and is calculated from the equation [2]:

$$
\Delta \mathrm{Rp}^{*}=\frac{\log R_{\text {pmax }}-\log R_{\text {min }}}{\log R_{\text {max }}} * 100
$$

where the $R_{\text {pmax }}$ and $R_{\text {pmin }}$ are the values of polarisation resistance maximum and minimum obtained in the cycles of ACET test, respectively. Thus, a lower $\Delta R p^{*}$ value means lower variation of the polarisation resistance during the cycles.

Figures 8 a-f show both the evolution of $\Delta R p^{*}$ calculated from the ACET results and the evolution of the parameters obtained after 641 hours in neutral salt spray, NSS, (rusting at the scribe, rusting on the panel, delamination at the scribe and delamination on the panel) versus anticorrosive pigment concentration, PVC. The evolution of the $\Delta R p^{*}$ parameter and the millimetres of rusting at the scribe are very similar for both pigments (Fig.8a and Fig. 8d), 6\% giving the best PVC (best anticorrosive performance) by means of electrochemical assay and salt fog spray test. If the coating contains an anticorrosive pigment, after 641 hours in the salt spray cabinet, the oxidation on the panel is $0 \%$ even at low doses (Fig $8 \mathrm{~b}$ and Fig 8e). That means that when the pigment dose is increased, there is no improvement in this parameter, the small observed differences could be explained due to error in the test or to inherent defects. At a longer exposure time probably it may be possible to see differences between them.

Adhesion properties evaluated by means of delamination at the scribe and delamination on the panel measurements in the salt fog spray test also improve with the addition of pigments. Although significant adhesion improvements are detected with a 3\% addition of any pigment, only small variations in the adherence results were detected at higher percentages except for panel delamination with Nubirox N2 coatings (Fig. 8c).

The results from the calculation of the parameter $\Delta R p^{*}$ show that further increases of PVC of anticorrosive pigments, whichever pigment was studied, are clearly better. Moreover, the results obtained by NSS confirm this behaviour for the Nubirox 106 coatings.

The use of a single electrochemical parameter such as $\Delta R p^{*}$ can be useful for determining the anticorrosive properties of a formulation obtained by the addition of 
different quantities of anticorrosive pigments and to obtain a certain correlation with salt fog spray resistance results. This correlation is only obtained when the same type of pigment formulations are compared.

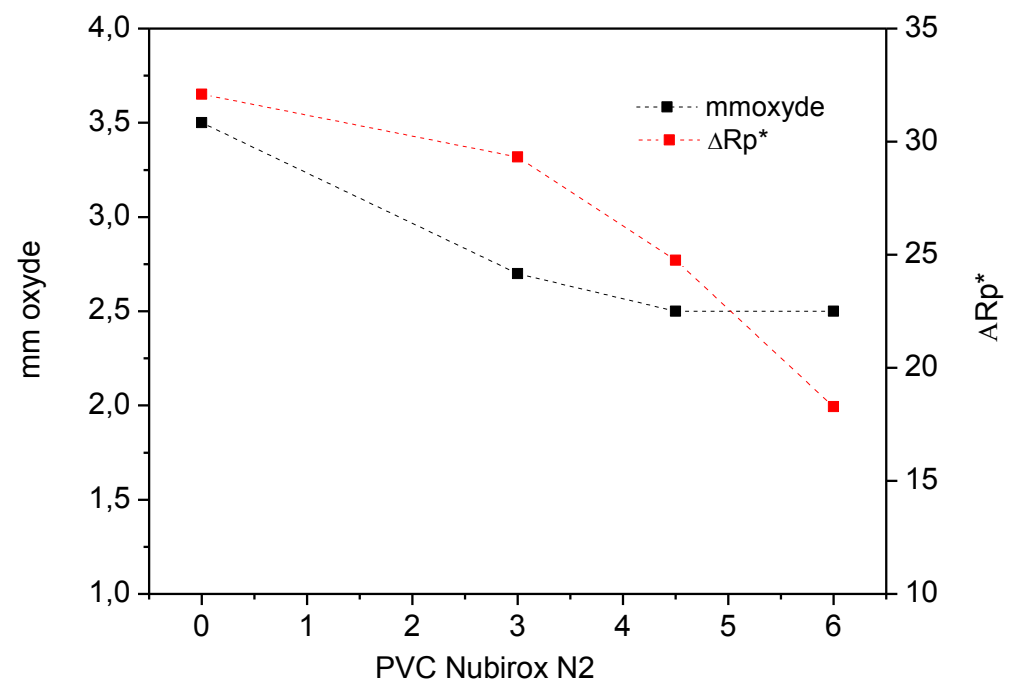

(a)

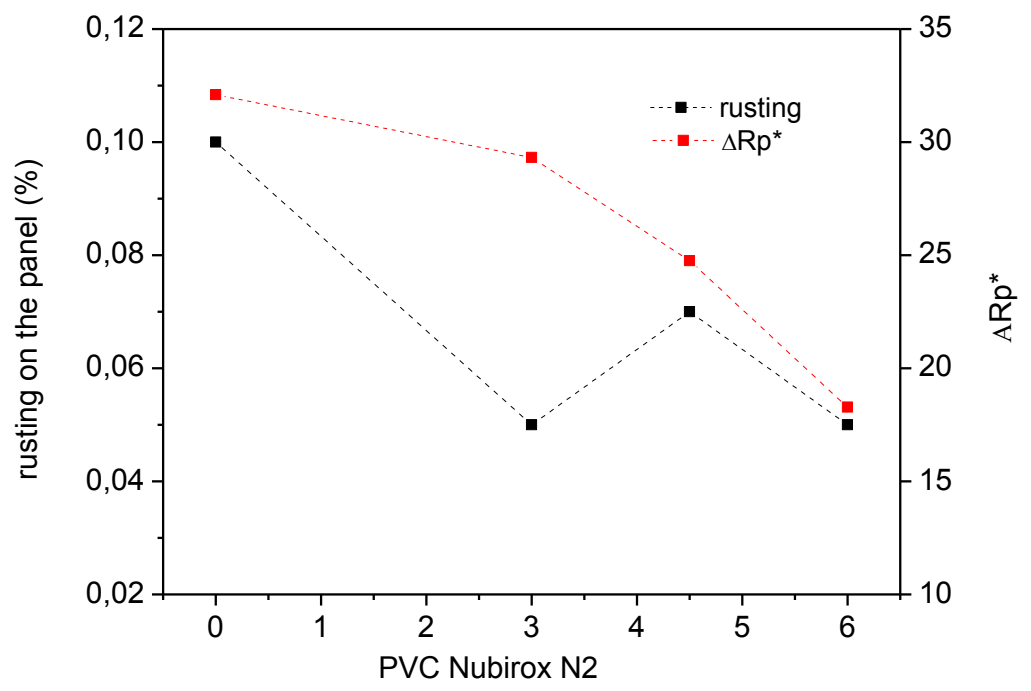

(b) 


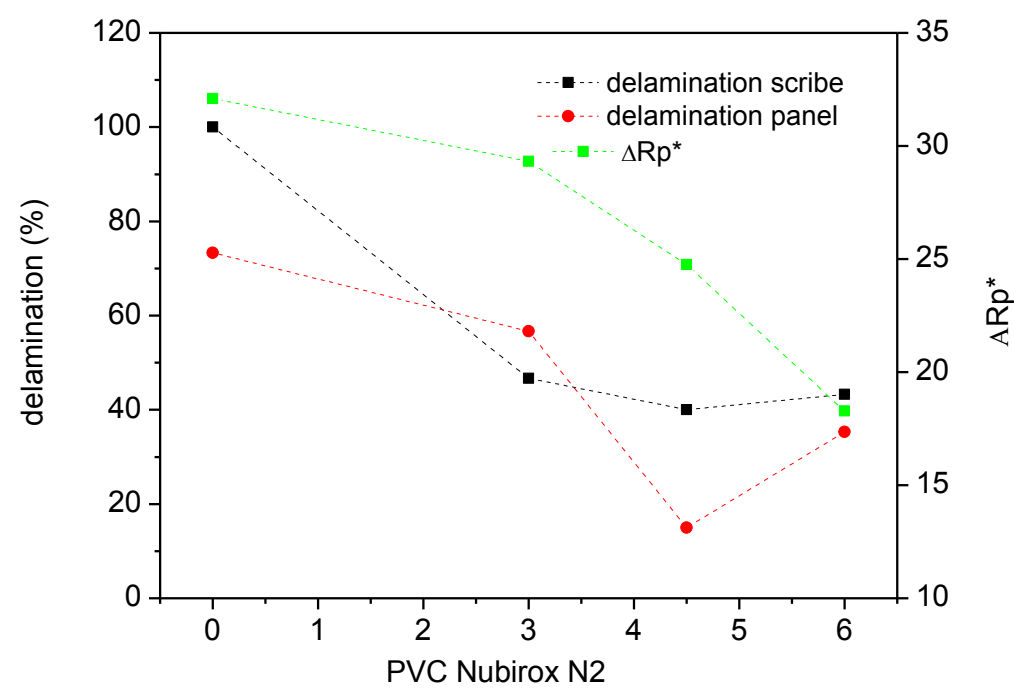

(c)

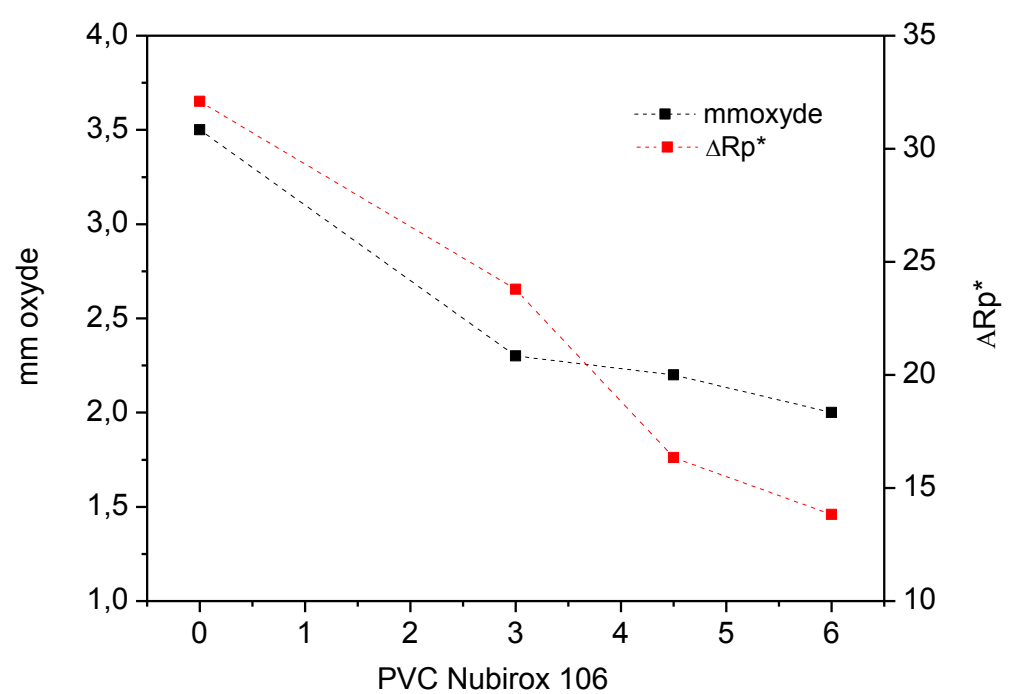

(d) 


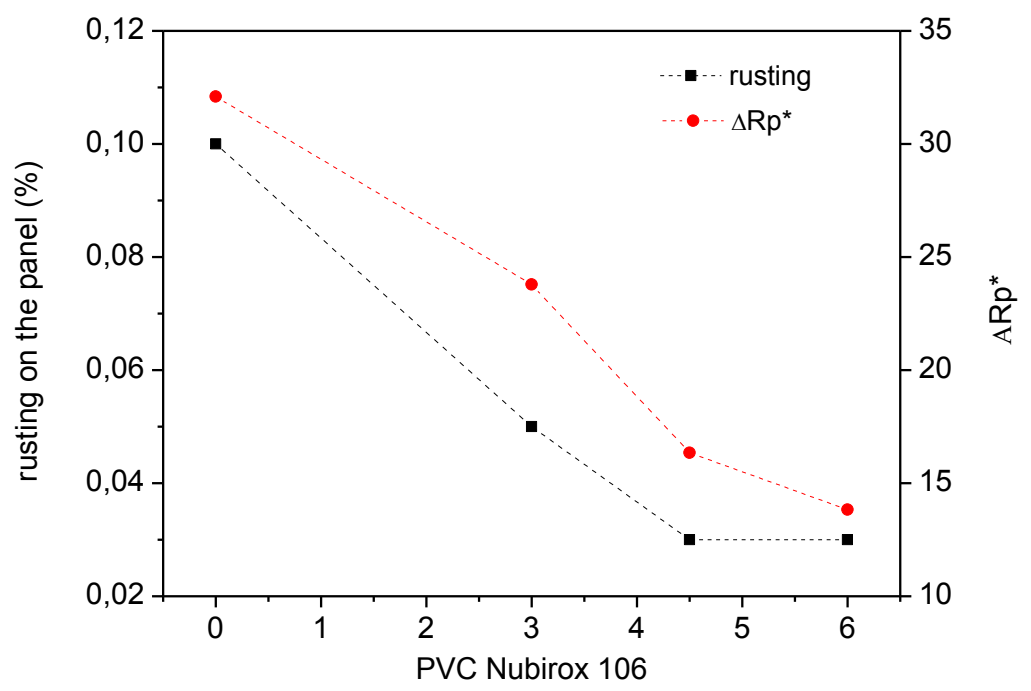

(e)

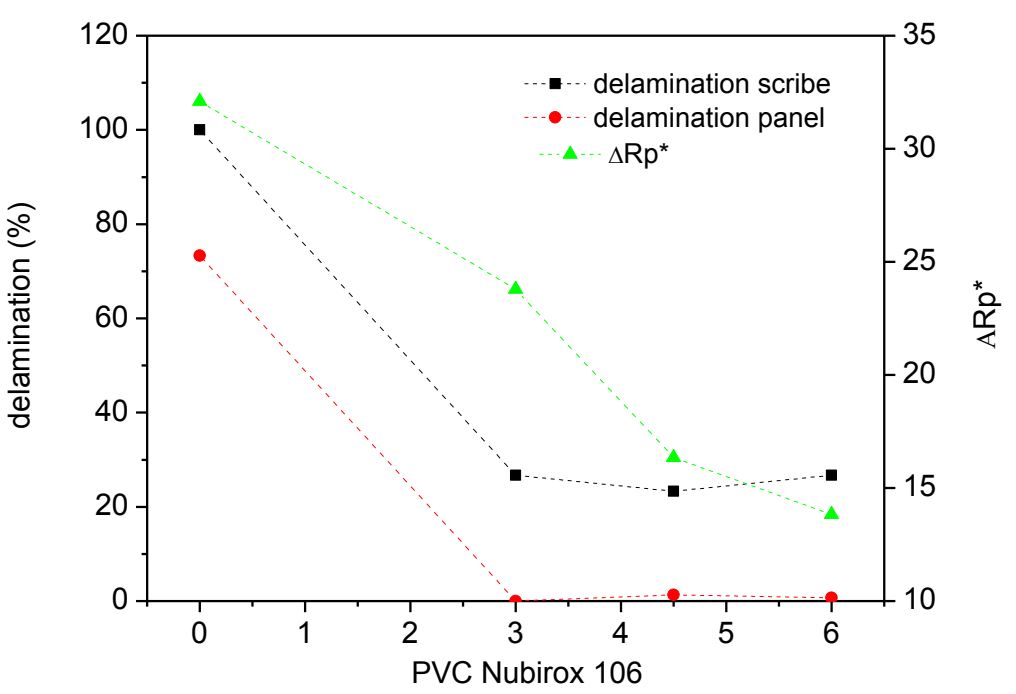

(f)

Fig. 8. Evolution of $\triangle R p^{*}$ and rusting at the scribe versus PVC, Evolution of $\triangle R p^{*}$ and rusting on the panel versus $\mathrm{PVC}$ and Evolution of $\triangle \mathrm{Rp} *$ and delamination versus $\mathrm{PVC}$ for the alkyd coatings with different pigments: Nubirox N2 (a, b, c), and Nubirox 106 (d, e, f); applied on cold rolled steel. 


\section{Conclusions}

The neutral salt spray test (NSS) and the accelerated cyclic electrochemical test (ACET) were used to investigate the effects of anticorrosive pigment addition (standard zinc phosphate or Nubirox N2 and modified zinc molybdenum phosphate or Nubirox 106 at $0,3,4.5$ and 6\%) in a solvent alkyd paint applied over cold rolled steel panels (CRS).

The experimental results of the NSS test revealed that the addition of both anticorrosive pigments to the alkyd paint exhibited a high inhibitory effect on the corrosion behaviour of the scratched coated steel. It was found that addition of the Nubirox 106 pigment decreased the corrosion generation rate in the scribe, as well as the coating delamination, significantly more than addition of the Nubirox N2 pigment.

ACET tests illustrated that the Nubirox N2 and the Nubirox 106 pigments improved the corrosion protection properties of the alkyd coating and that the higher the dose the better the result. The alkyd coating containing 6\% of Nubirox 106 pigment showed the highest interface stability and the lowest delamination area.

A new parameter $\Delta R p^{*}$ based on the variation of the polarisation resistance from ACET test, was introduced with the aim of characterising the anticorrosive performance of the coatings.

The results from ACET and NSS were correlated using the parameter $\Delta R p^{*}$ and the NSS parameters were evaluated. This study confirms the existence of a correlation between the techniques when using a single pigment. The best anticorrosive coating obtained in this study was formulated with $6 \%$ of Nubirox 106 , followed by the coating with $6 \%$ of Nubirox N2, with a significant improvement compared with the results obtained using the reference coating.

\section{Acknowledgments}

Authors would like to thanks Ms $\mathrm{M}^{\mathrm{a}}$ Carmen Güiza and Mr Victor Lozano for their help in the development of this study.

\section{References}

[1] A. Forsgren, Corrosion control through organic coatings, CRC Press, Boca Ratón (Florida), 2006. 
[2] D. Mills, S. Mabbutt, G. Bierwagen, Investigation into mechanism of protection of pigmented alkyd coatings using electrochemical and other methods, Prog. Org. Coatings. 46 (2003) 176-181. doi:10.1016/S0300-9440(02)00187-X.

[3] C. Deyá, G. Blustein, B. del Amo, R. Romagnoli, Evaluation of eco-friendly anticorrosive pigments for paints in service conditions, Prog. Org. Coatings. 69 (2010) 1-6. doi:http://dx.doi.org/10.1016/j.porgcoat.2010.03.011.

[4] B. Chico, J. Simancas, J.M. Vega, N. Granizo, I. Díaz, D. de la Fuente, et al., Anticorrosive behaviour of alkyd paints formulated with ion-exchange pigments, Prog. Org. Coatings. 61 (2008) 283-290. doi:10.1016/j.porgcoat.2007.07.033.

[5] C. Simpson, Improved corrosion-inhibited pigment, Chemtech. 27 (1997) 40-42.

[6] G. Blustein, M.C. Deyá, R. Romagnoli, B. del Amo, Three generations of inorganic phosphates in solvent and water-borne paints: A synergism case, Appl. Surf. Sci. 252 (2005) 1386-1397. doi:10.1016/j.apsusc.2005.02.096.

[7] L. Chromy, E. Kamińska, Non-toxic anticorrosive pigments, Prog. Org. Coatings. 18 (1990) 319-324. doi:http://dx.doi.org/10.1016/0033-0655(90)85014-O.

[8] G. Grundmeier, B. Rossenbeck, K.J. Roschmann, P. Ebbinghaus, M. Stratmann, Corrosion protection of Zn-phosphate containing water borne dispersion coatings: Part 2: Investigations of the corrosive de-adhesion of model latex coatings on iron, Corros. Sci. 48 (2006) 3716-3730. doi:http://dx.doi.org/10.1016/j.corsci.2006.01.007.

[9] Y. Shao, C. Jia, G. Meng, T. Zhang, F. Wang, The role of a zinc phosphate pigment in the corrosion of scratched epoxy-coated steel, Corros. Sci. 51 (2009) 371-379. doi:10.1016/j.corsci.2008.11.015.

[10] Y. Hao, F. Liu, E.-H. Han, S. Anjum, G. Xu, The mechanism of inhibition by zinc phosphate in an epoxy coating, Corros. Sci. 69 (2013) 77-86. doi:10.1016/j.corsci.2012.11.025.

[11] M. Bethencourt, F.J. Botana, M. Marcos, R.M. Osuna, J.M. Sánchez-Amaya, Inhibitor properties of "green" pigments for paints, Prog. Org. Coatings. 46 (2003) 280-287. doi:10.1016/S0300-9440(03)00013-4.

[12] P. Kalenda, a. Kalendová, D. Veselý, Properties of anticorrosion pigments depending on their chemical composition and PVC value, Pigment Resin Technol. 35 (2006) 188-199. doi:10.1108/03699420610677181.

[13] A. Kalendová, D. Veselý, J. Brodinová, Anticorrosive spinel-type pigments of the mixed metal oxides compared to metal polyphosphates, Anti-Corrosion Methods Mater. 51 (2004) 6-17. doi:10.1108/00035590410512681.

[14] Z. Yong, J. Zhu, C. Qiu, Y. Liu, Molybdate/phosphate composite conversion coating on magnesium alloy surface for corrosion protection, Appl. Surf. Sci. 255 (2008) 1672-1680. doi:http://dx.doi.org/10.1016/j.apsusc.2008.04.095. 
[15] C. Dehghanian, M. Saremi, M. Mohammadi Sabet, Investigation into synergistic effect of molybdate and phosphate as an inhibitor for mild steel corrosion prevention in simulated cooling water, Iran. J. Mater. Sci. Eng. 2 (2005) 9-15.

[16] M.J. Gimeno, S. Chamorro, R. March, E. Oró, P. Pérez, J. Gracenea, J.J. Suay, Anticorrosive properties enhancement by means of phosphate pigments in an epoxy 2k coating. Assessment by NSS and ACET, Prog. Org. Coatings. 77 (2014) 2024-2030. doi:10.1016/j.porgcoat.2014.04.004.

[17] M. Puig, M.J. Gimeno, J.J. Gracenea, J.J. Suay, Anticorrosive properties enhancement in powder coating duplex systems by means of ZMP anticorrosive pigment. Assessment by electrochemical techniques, Prog. Org. Coatings. 77 (2014) 1993-1999. doi:10.1016/j.porgcoat.2014.04.031.

[18] B. del Amo, L. Véleva, A.R. Di Sarli, C.I. Elsner, Performance of coated steel systems exposed to different media, Prog. Org. Coatings. 50 (2004) 179-192. doi:10.1016/j.porgcoat.2004.02.003.

[19] B.S. Skerry, C.H. Simpson, Corrosion and Weathering of Paints for Atmospheric Corrosion Control, Corrosion. 49 (1993) 663-674. doi:10.5006/1.3316098.

[20] J.N. Murray, L.D. Stephenson, A. Kumar, Electrochemical and physical evaluations of coil coatings on metal-coated steels for roofing applications, Prog. Org. Coatings. 47 (2003) 136-146. doi:10.1016/S0300-9440(03)00114-0.

[21] T. Prosek, A. Nazarov, J. Stoulil, D. Thierry, Evaluation of the tendency of coilcoated materials to blistering: Field exposure, accelerated tests and electrochemical measurements, Corros. Sci. 61 (2012) 92-100. doi:10.1016/j.corsci.2012.04.026.

[22] ASTM B117 - Standard Practice for Operating Salt Spray (Fog) Apparatus, (n.d.).

[23] ASTM D-3359 Standard Test Methods for Measuring Adhesion by Tape Test, (n.d.).

[24] ASTM D 1654-92 (Reapproved 2000). Standard Test Method for Evaluation of Painted or Coated Specimens Subjected to Corrosive Environment., (n.d.).

[25] ASTM D610-01. Standard Test Method for Evaluating Degree of Rusting onPainted Steel Surfaces., (n.d.).

[26] ISO 17463:2014, Paints and Varnishes. Guidelines for the determination of anticorrosive properties of organic coatings by accelerated cyclic electrochemical technique.

[27] A. Miszczyk, K. Darowicki, Multivariate analysis of impedance data obtained for coating systemsof varying thickness applied on steel, Progress in Organic Coatings 77 (2014) 2000-2006. 
Página $\mathbf{2 2}$ de $\mathbf{2 2}$ 